\title{
Objeto, memória e afeto: uma reflexão
}

\section{Object, memory and affection: a reflection}

Enviado em: 12/04/2017

Aceito em: 03/06/2017

NERY, Olivia Silva ${ }^{1}$

\begin{abstract}
Resumo:
Sejam objetos banais ou relíquias, eles podem desempenhar papéis importantes na construção da identidade, personalidade, e com vínculos memoriais dos sujeitos. Possuem a capacidade de serem evocadores memoriais e narradores de histórias. Nesse sentido, esse ensaio apresenta uma reflexão sobre o poder memorial e afetivo que alguns objetos possuem na vida dos indivíduos. Nesse caso, apresentamos aqui os objetos que pertenceram a Lyuba Duprat (1900-1994), que lecionou durante décadas a língua francesa na cidade do Rio Grande, Rio Grande do Sul.
\end{abstract}

Palavras-chave: Objetos, memória, afeto.

\begin{abstract}
:
Whether they be everyday objects or historical relics, objects can play important roles in the creation of people's identities, personalities, and memories. Objects possess the capacity to evoke memories and narrate the past. It is in this spirit that this essay reflects on the affective and memorial power that certain objects hold in the lives of individuals. In this particular case, we examine objects belonging to Lyuba Duprat (1900-1994), a woman who imparted French language instruction in the southern Brazilian city of Rio Grande - RS for many decades.
\end{abstract}

Keywords: Objects, memory, affection

\footnotetext{
${ }^{1}$ Historiadora, Mestre em Memória Social e Patrimônio Cultural (UFPEL); Doutoranda em História pela PUCRS, bolsista CAPES.
} 


\section{Conhecendo os objetos e seus cenários}

Ao observarmos nosso entorno podemos perceber que estamos cercados por inúmeros objetos, como assim já observou Abraham Moles (1972) e Jean Baudrillard (1972) ao questionarem a necessidade de criarmos um inventário para que pudéssemos organizar e entender os objetos que nos cercam. Assim, os objetos vinculados aos indivíduos podem dizer muito sobre eles, tanto aqueles que estão mais próximos do corpo, a exemplo daqueles que compõem a indumentária e a vestimenta, quanto os que ficam escondidos em gavetas, em caixas ou expostos nas estantes domésticas. Esses objetos que são guardados e preservados pelo seu dono, aos poucos podem vir a adquirir um valor sensível e uma importância simbólica tanto para ele próprio quanto para os outros indivíduos, que por ventura estiverem na sua presença, principalmente para as pessoas mais próximas.

Nesse sentido, esse ensaio expõe os resultados parciais da pesquisa de mestrado que abordou a relação dos objetos com a memória, os indivíduos, e os aspectos simbólicos e imateriais que permeiam 0 universo da materialidade. Buscamos nos aproximar da proposta trazida pelo autor francês Thierry Bonnot (2014) quando afirma que as Ciências Humanas e Sociais devem passar de um estudo sobre objetos como formas de um saber sobre os homens na sociedade, para um estudo historicamente situado nos objetos, sua relação com os homens e sua influência nos indivíduos (BONNOT, 2014).

Os objetos estudados pertenceram à professora de francês Lyuba Duprat (Rio Grande, 1900-1994) que lecionou mais de 70 anos a língua francesa na cidade do Rio Grande, extremo sul do Rio Grande do Sul, e atualmente estão salvaguardados em instituições memoriais - como o Museu da Cidade do Rio Grande (MCRG) e a Salle de Documenation Lyuba Duprat da Universidade Federal do Rio Grande - FURG - ou nas residências de amigos e ex-alunos da professora. 
Assim, o trabalho, baseado em entrevistas orais, proporcionou um entendimento mais aprofundado sobre as pontes de memória que os objetos dessa professora despertavam em seus ex-alunos, formando uma rede de memórias, esquecimentos e narrativas a partir dos vestígios de Lyuba. Inicialmente foram estudados aqueles que fazem parte do acervo das instituições supracitadas, entretanto, os objetos que estavam guardados nas casas de entes queridos da professora, mostraram-se, eventualmente, mais importantes e simbólicos para os entrevistados do que os do Museu e da Salle.

Tal resultado nos motivou a buscar o que havia "por trás" desses objetos, entender o que eles representavam para seus guardiões e o que os diferenciava daqueles musealizados. Esse acompanhamento da trajetória de alguns vestígios que estavam deslocados das instituições memoriais, desvendou uma rede de afeto e de emoção relacionados aos objetos que estavam na casa dos ex-alunos entrevistados. O que observamos foi a existência de uma forte relação de afeto e emoção com esses vestígios. Eles eram objetos afetivos, conforme o conceito apresentado por Véronique Dassié, sob os quais existe um cuidado, um valor patrimonial atribuído, são âncoras memoriais que conectam memórias e identidades dos sujeitos e suas famílias (DASSIÉ, 2010). A narrativa, o olhar, o cuidado no momento do toque e do uso desses objetos que pertenceram a Lyuba Duprat eram latentes: não se tratavam de meros objetos.

Alguns deles foram passados ainda em vida por Lyuba Duprat, em forma de presente, outros no momento do inventário. Esses objetos, mesmo que de maneiras diferentes, apresentaram uma carga simbólica e afetiva dentro de sua nova moradia, as casas dos seguintes ex-alunos: Nubia Hanciau, Flavio Hanciau, e Ricardo Soler.

Começamos pelo espaço mais íntimo e que é detentor de uma quantidade de símbolos e significados muito grande - a casa. O espaço da casa é um universo individual, íntimo e familiar, que abarca toda a complexidade da relação entre público e privado. A maneira como os espaços e os cômodos são distribuídos, a forma como os objetos estão expostos (ou não) e a seleção de quem entra na casa e em cada cômodo faz com que o espaço doméstico seja carregado de complexidade e ao mesmo tempo seja uma extensão da vida, da cultura e da posição do indivíduo na sociedade.

Para Bachelard "a casa é o nosso canto do mundo. Ela é, como se diz amiúde, o nosso primeiro universo. É um verdadeiro cosmos. Um cosmos em toda acepção do 
termo" (1993, p. 24). A casa é composta não só por paredes, telhados e pinturas, é composta por móveis e objetos de várias categorias. Ao entrar na própria casa, o indivíduo entra realmente em outro universo, em um espaço onde reproduz o seu estilo de vida, os seus sonhos, desejos, medos, memórias e esquecimentos.

Ao entrar na casa de outra pessoa percebemos a disposição das coisas dentro do espaço, o tamanho dos cômodos, a presença ou não de fotografias, objetos decorativos e demais materiais que compõem o cenário doméstico. Os cômodos mais íntimos são espaços mais secretos, onde o acesso não é tão permitido e utilizado como os outros. Dentro do quarto é que estão os objetos mais íntimos, os maiores segredos. A partir da reflexão de Bachelard (1993) e de Bernardes (2010), a casa é o espaço aonde se guardam as memórias, as relíquias, os segredos e os esquecimentos. Ao fazer o simples exercício de fechar os olhos e se imaginar entrando na sua própria casa ou na casa de algum familiar, várias coisas são lembradas e outras esquecidas.

Bachelard afirma que "é graças à casa que um grande número de nossas lembranças estão guardadas; e quando a casa tem um porão, um sótão, cantos e corredores, nossas lembranças têm refúgios cada vez mais bem caracterizados" (BACHELARD, 1993, p. 28). Dessa maneira, lembramos principalmente das casas em que se viveu e daquelas de pessoas próximas, as de familiares, por exemplo.

A casa e todas as suas composições, significados e memórias mostram um universo particular onde poucos, e somente aqueles que os donos desejam, têm acesso. Para Joana Bernardes (2010), a casa pode contar a história do seu habitante, assim como as coisas que estão dentro dela. Sendo assim, é possível compreender um pouco mais a vida de alguém a partir do entendimento desse espaço e também do cenário que o compõe (os objetos). Afinal, a casa é onde o indivíduo pode ser ele mesmo, é o seu "canto", onde não há tanta preocupação com o olhar dos outros. Sobre isso, Ecléa Bosi traz a seguinte reflexão:

[...] o espaço que ela vivencia, como o dos primitivos, é mítico, heterogêneo, habitado por influências mágicas. A mesa da família possui um lado onde é bom comer, o lado fasto ode senta-se mamãe e é agradável estar; no lado de lá, o retrato do tio-avô que me olha fixo, às vezes feroz, torna o lado nefasto onde eu recuso comida e choramingo. Tudo é tão penetrado de artefatos, móveis, cantos, portas e desvãos, que mudar é perder uma parte de si mesmo; é deixar para trás lembranças que precisam desse ambiente para reviver. (BOSI, 1994, p. 436) 
O autor Rafael Iglesia afirma que dentro do espaço privado, cada móvel e cada canto da casa é investido de uma função e também de uma dignidade simbólica. Para ele, todos os seres e objetos estão conectados dentro da casa, eles são cúmplices do cotidiano familiar e dos seus hábitos e carregam um valor afetivo que é marcado por sua presença (IGLESIA, 2011). Ferreira afirma que "[..] são, portanto, as narrativas pessoais que dão aos objetos dilacerados pelo tempo, [...] o sentido de patrimônio" (FERREIRA, 2008, p. 37). Assim, essa relação afetiva que temos com aquilo que é visto como patrimonial é mediada, segundo a autora, pelas narrativas pessoais que envolvem sua materialidade.

Dentro das residências dos entrevistados alguns objetos apresentam funções híbridas: são utilizados em suas funções normais, fazem parte da rotina casa e estão misturados com os outros utensílios domésticos, ao mesmo tempo em que são vistos como relíquias. Já outros são apenas expostos, relembrando uma espécie de altar de homenagem; ou, ainda, são guardados em locais seguros, fora do olhar da maioria. Gonçalves advoga que mesmo que os objetos continuem funcionando para aquilo que foram fabricados, alguns acabam adquirindo uma função mágico-simbólica e religiosa. "Não são, desse modo, meros objetos" (GONÇALVES, 2005, p. 18), possuem uma personalidade que está diretamente relacionada com a personalidade de seu proprietário, conceito que pode ser associado ao de "extended-self", desenvolvido por Ulpiano Bezerra de Meneses (1998), o qual demonstra que os objetos podem ser vistos enquanto extensões de seus proprietários.

Durante a visita à casa dos entrevistados, cada objeto pertencente à Lyuba Duprat mostrado por eles trazia consigo muitas histórias. Eles contavam um pouco sobre a vida e utilidade das peças quando pertenciam à professora Lyuba e agora, aos seus cuidados. O ato de contar as histórias e funções dos objetos feito por seus proprietários é destacada como importante para Véronique Dassié pois, a história dos objetos e suas trajetórias devem ser reconstituídas a partir dos testemunhos de seus guardiões (DASSIÉ, 2010).

\section{Cada objeto uma memória, uma história, uma emoção.}

O primeiro objeto analisado dentro do contexto doméstico do casal Flavio e Nubia Hanciau é uma chapeleira (Figura 1) que acompanha outros objetos que pertenciam à professora:um porta-retrato com uma fotografia de Lyuba Duprat, dois 
moedeiros e, no local onde se guardam as bengalas, a bengala que pertencia ao pai de Lyuba, Augusto Duprat.

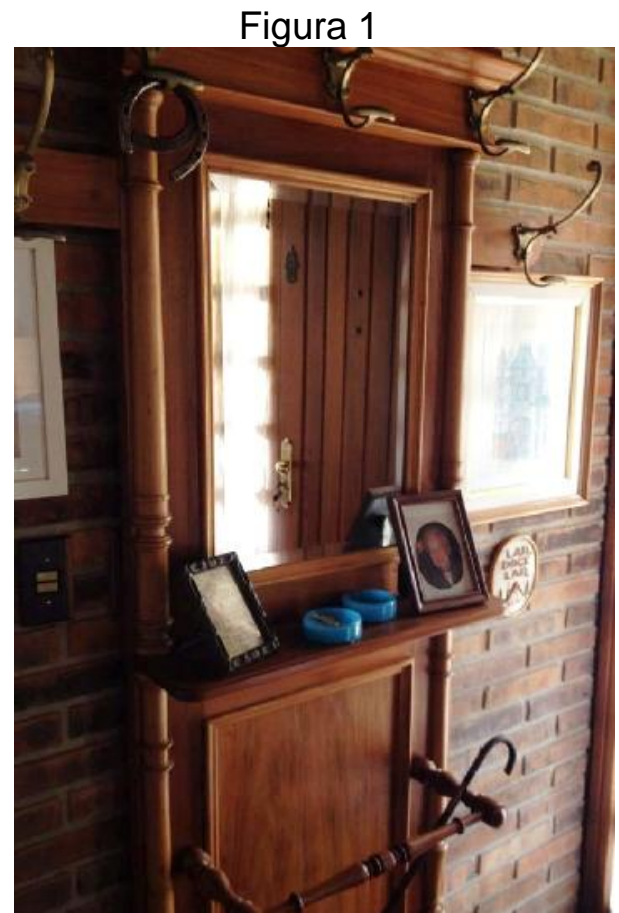

Chapeleira de Lyuba Duprat, 2014. Fonte: Foto da Autora, 2014. Objetos pertencentes ao Sr. Flavio e Sra. Nubia Hanciau

\section{Ao falar do móvel e dos objetos nele colocados, Flavio Hanciau rememora:}

[...] no final da vida ela me presenteou. É interessante, porque depois que eu me casei ela me oferecia sempre a bengala do pai, e o chapeleiro. Eu sempre dizia que gostava, mas que não queria nada dela, apenas a companhia, a alegria. Então numa tarde ela disse: "Você vai levar, hoje você vai levar, é importante que tu leves", e naquela madrugada ela faleceu. Parecia que ela pressentiu que algo ia ocorrer. A bengala eu guardo aqui na minha casa, com o chapeleiro, com o porta-moedas. Porque ela pegava uma moedinha de dez centavos e dava para a pessoa que passava na casa dela, que era sempre agraciada com uma moedinha, e até nisso ela tinha uma atitude interessante, porque ela se preparava para cada momento, para as pessoas que chegavam na casa dela.

\footnotetext{
${ }^{2}$ Entrevista de Flavio Hanciau em 12 de janeiro de 2015. Rio Grande, RS.
} 
Dessa forma, através das lembranças do senhor Flavio, verificamos a importância que esses objetos têm na vida dos entrevistados e a representatividade que possuem no espaço doméstico do casal. Levando em consideração a localização destes objetos, a seleção, a disposição, a organização do conjunto, e o valor a eles atribuído, eles são representativos de uma homenagem à Lyuba na casa de Flavio e Nubia Hanciau, principalmente pelos elementos que o compõem: a foto, a bengala, o quadro em francês e os objetos em sua posição original.

O significado destes objetos nos conduz à reflexão acerca da sua imaterialidade, sua possível "alma". O antropólogo Marcel Mauss revela, em sua obra Sociologia e Antropologia, como um grupo de indígenas das regiões da Polinésia realizava uma forma de troca e contrato envolvendo objetos, mas também serviços, festas, banquetes, etc. (MAUSS, 2003). Ao observar essa troca de "presentes", que inicialmente parecia ser voluntária, o autor percebeu que esses presentes tinham um hau. O hau é o espírito das coisas, não só dos objetos, mas também das florestas e animais. O que se aproxima dessa pesquisa, basicamente, é a questão espiritual e simbólica que os indivíduos atribuem aos objetos - essa transmissão de dons, esse vínculo criado pela troca, é também um vínculo de almas, "pois a própria coisa tem uma alma, é uma alma. De onde resulta que apresentar alguma coisa a alguém é apresentar algo de si" (MAUSS, 2003, p. 200).

Assim, presentear o outro com algum objeto que foi seu é dar um pouco de si para a pessoa, é doar-se junto com a materialidade. Ele passa a ser representativo do seu doador e também do receptor; assim, "aceitar alguma coisa de alguém é aceitar algo de sua essência espiritual, de sua alma; a conservação dessa coisa seria rigorosa e mortal, pois [...] essas coisas vem da pessoa, não apenas moralmente, mas física e espiritualmente"(MAUSS, 2003, p. 200). Essa reflexão pode ser associado aos objetos recebidos pelos ex-alunos de Lyuba Duprat são também formas de representação da própria professora, são partes dela e, por isso, recebem conservação e atenção especial.

A alma das coisas também foi estudada por José Reginaldo Gonçalves, que, na apresentação do seu livro Alma das coisas, sugere que apesar de termos muitos objetos em nossas vidas, nossa sociedade desaprendeu a falar a língua deles. Para ele, "é provável que a alma das coisas ainda nos afete secretamente" (GONÇALVES, 2013, p. 8). 
[...]enquanto portadoras de uma "alma", de um "espírito", as coisas não existem isoladamente, como se fossem entidades autônomas; elas existem efetivamente como parte de uma vasta e complexa rede de relações sociais e cósmicas, nas quais desempenham funções mediadoras fundamentais entre a natureza e cultura, deuses e seres humanos, mortos e vivos, passado e presente, cosmos e sociedade, corpo e alma, etc. (MAUSS, 2003, p. 200) .

As ideias de Gonçalves parecem corroborar as apresentadas pelos autores Flavio Silveira e Manuel Lima Filho, pois para eles os objetos fazem parte de um universo criado por nós, ao atribuirmos valores simbólicos a eles, recebem uma aura, uma fonte de comunicação que fala sobre quem somos, nosso lugar no mundo. Eles também são "vias de comunicação relacionadas a determinadas experiências culturais" (SILVEIRA e LIMA FILHO, 2005, p. 38). São exatamente esses diversos sentidos que os objetos possuem que lhes permitem a capacidade de evocar memórias "e experimentar a tensão entre esquecimentos e lembranças, a partir do contato com a materialidade da coisa e os sentidos possíveis que ela encerra consigo" (SILVEIRA e LIMA FILHO, 2005, p. 38).

Os objetos podem ser mais especiais para algumas pessoas do que para outras. Aquelas que se sentem fascinadas pelo universo material e por sua biografia, veem nas coisas mais do que matéria. Clarice Lispector dá um exemplo disso em seu livro Um Sopro de Vida, o qual narra sobre a vida de um escritor e a relação complicada que ele tem com seu alterego, Ângela. Os dois, o escritor e Ângela, estão escrevendo um livro, ela decide escrever sobre as coisas: "nem sei como começar. Só sei que vou falar no mundo das coisas. Eu juro que a coisa tem aura" (LISPECTOR, 1999, p. 103). Ângela refere-se a tudo que é concreto, material, mas também às palavras, e o que "concretiza-se". Em seu livro ela conta sobre a sua relação com armários, bules, relógios, carro, etc. Cada um com uma aura, um papel, ela dá vida e personalidade àquilo que parece imóvel, humaniza o objeto solitário: "[...] mas o broche é sério. É um argumento. Lança-se no ar como uma mulher-gazela. Ele prende, ele pesa, ele espera. E quando é desfechado—tudo fica nu, caem os panos e os seios brancos parecem róseos. O broche é um ponto final” (LISPECTOR, 1999, p. 103).

A obra literária de Clarice Lispector mostra com delicadeza a imaterialidade dos objetos. Dá a dimensão de como são importantes para a construção da identidade, da vida de cada indivíduo. Ao falar da aura que as coisas possuem, e ao defini-las, escreve: 
[...] o que se chama de "coisa" é a condensação sólida e visível de uma parte de sua aura. A aura da coisa é diferente da aura da pessoa. A aura desta flui e reflui, se omite e se apresenta, se adoça ou se encoleriza em púrpura, explode e se implode. Enquanto a aura da coisa é igual a si mesma o tempo todo. A aura qualifica as coisas. [...] De agora em diante estudarei a profunda natureza morta dos objetos vistos com delicada superficialidade, e proposital, porque se não fosse superficial se afundaria em passado e futuro da coisa. (LISPECTOR, 1999, p. 105).

Talvez seja então a aura das coisas que os qualifiquem como diferentes e importantes dentro de um contexto. Podem ser representações dos sujeitos e, além disso, da alma das pessoas e de todos que, de alguma forma, possuem com elas conexões. Entretanto, conforme nos relembra Thierry Bonnot (2014), os objetos não nascem com tais funções e significados, são atribuídos durante sua trajetória de vida social e sua relação com os sujeitos.

O segundo objeto analisado é o conjunto de licoreiro (Figura 2), também pertence ao casal Hanciau,e, segundo os entrevistados, Lyuba Duprat utilizava para servir vinho do porto para seus alunos e visitas.

Figura 2

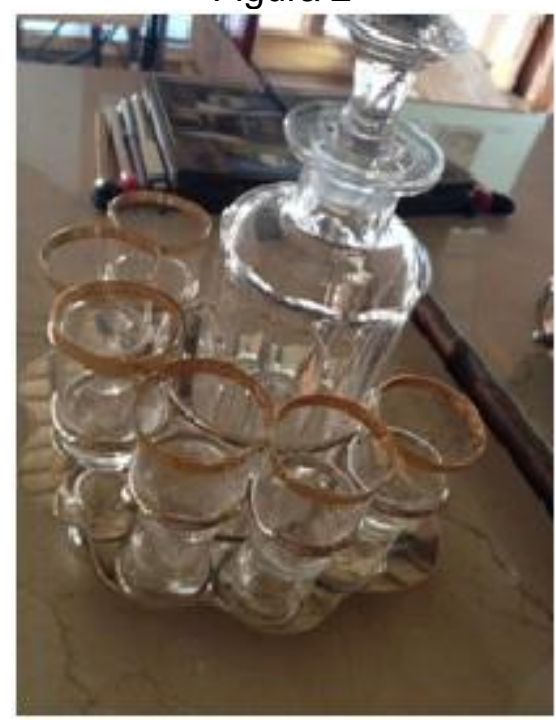

Licoreiro e cálices de cristal, sem data. Foto da Autora, 2014. Objeto pertencente ao Sr. Flavio e Sra. Nubia Hanciau

Ele fica agora na sala principal da casa, mas nem sempre está exposto ao olhar de quem por ali passa, às vezes está guardado para preservar sua integridade material. Ao mostrá-lo, Nubia relembra sobre o ritual feito por Lyuba ao recepcionar seus convidados. O casal possui alguns copos e taças de cristal que pertenciam à professora acomodados em uma cristaleira. Segundo ela, são pouco utilizados a fim 
de conservá-los, pois são muito delicados e importantes para o casal. A preservação dos objetos está diretamente relacionada a uma função memorial e identitária que esses vestígios têm em relação aos seus proprietários:

[...] o carinho, caminho para ser considerado como a alma do objeto, se torna a razão para a sua conservação e assume a memória do que é suposto ser preenchido. Então, esses são "objetos de afeto" na medida em que os sentimentos são o princípio do compromisso mostrado a eles e parece impossível para os seus titulares de se separar deles (DASSIÉ, 2009, p.2010 - tradução livre da autora).

São, acima de tudo, objetos afetivos que carregam em sua materialidade um universo de imaterialidades, de lembranças, histórias, narrativas, identidades e esquecimentos. Assim, a maioria dos objetos que hoje estão nos espaços domésticos analisados, mostraram-se representativos de um vínculo vivo com a professora Lyuba.

O terceiro objeto é um pequeno vaso de pedra sabão com cachos de uva em vidro (Figura 3), localizado na mesa de centro da sala do casal, mas antes, segundo os entrevistados, fazia parte da decoração da sala onde Lyuba Duprat ministrava suas aulas. Segundo Nubia, seria quase impossível encontrar um aluno da professora que não lembrasse desse objeto, demonstrando sua importância no cenário em que a Lyuba vivia e lecionava.

Figura 3

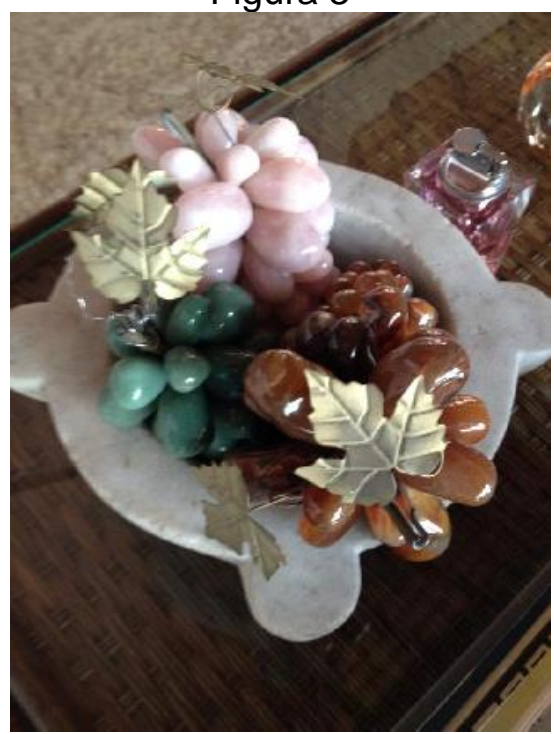

Objeto decorativo, uvas em vidro, 2014. Fonte: Foto da Autora, 2014. Objeto pertencente ao Sr. Flavio e Sra. Nubia Hanciau 
A senhora Regina Carmem, outra ex-aluna entrevistada durante a pesquisa de Mestrado, se emocionou ao visualizar a fotografia acima, disse ter sentido uma forte emoção em rever o objeto, como se trouxesse tudo à tona em sua memória ${ }^{3}$. Sobre esse objeto, o senhor Flavio Hanciau, reforçou que os cachos de uva foram um presente seu e de seu pai para Lyuba Duprat, como lembrança de uma viagem que ambos fizeram para Ouro Preto.

As histórias contadas sobre os objetos acabaram transferindo discursos e sentimentos para sua materialidade. Eles adquiriram valor memorial e patrimonial dentro das casas e famílias e são, geralmente, insubstituíveis, não são abandonados, apenas passados de geração para geração ou entregues às pessoas que são muito próximas à família. Seu valor simbólico, memorial e também espiritual (BOSI, 1994).

Pela atitude dos entrevistados, é possível dizer que os objetos mostrados anteriormente são vistos como relíquias e patrimônios da família e da casa, que provavelmente ficarão nesse cenário por muito tempo. Outro objeto que pode ser encontrado na residência de Flavio e Nubia Hanciau é o porta-salgados, ele é relembrado por Nubia como um utensílio muito usado por Lyuba, e que mostra o seu hábito de receber bem os seus convidados. Segundo os entrevistados, ela servia, em algumas datas especiais, salgados ainda quentes no recipiente acima. Segundo Nubia, devido a sua qualidade material, às vezes também é usado por eles como um objeto híbrido que, conforme dito anteriormente, é aquele que é utilizado de acordo com sua função original, quando às vezes é deslocado ou recebe um caráter simbólico diferenciado. O fato de alguns objetos serem utilizados de acordo com sua função original não retira a importância simbólica atrelada a eles, mas sim, de alguma maneira, acaba incluindo outras. E o uso diário dos objetos, segundo Bachelard, criam vínculos entre presente e passado:

[...] os objetos assim acariciados nascem realmente de uma luz íntima; chegam a um nível de realidade mais elevado que os objetos indiferentes, que os objetos definidos pela realidade geométrica. Propagam uma nova realidade de ser. Assumem não somente o seu lugar numa ordem, mas uma comunhão de ordem. Entre um objeto e outro, no aposento, os cuidados domésticos tecem vínculos que unem um passado muito antigo ao dia novo. A arrumadeira desperta os móveis adormecidos (BACHELARD, 1993, p. 80)

\footnotetext{
${ }^{3}$ Regina Carmem Dolci. Rio Grande/RS. 18 de dezembro de 2014. Entrevista concedida à Olivia Silva Nery.
} 
Assim como o casal Hanciau, o ex-aluno Ricardo Soler possui, em sua residência, diversos móveis que pertenceram à sua professora de francês. Alguns foram remodelados e restaurados, mas compõem junto com outros objetos o espaço da sala e escritório do entrevistado. Segundo Ricardo, ela mantinha a mesma disposição que é mantida por ele até hoje. Em visita a sua casa, Ricardo contou que nas ocasiões em que recebe visitantes que conheceram à professora Lyuba ou que se interessam pelo mobiliário, ele conta um pouco da história desses móveis e objetos, fazendo referência à sua antiga proprietária. Assim, não se trata de um móvel com objetos quaisquer, mas de um conjunto de elementos que agregados são formadores de um aparato simbólico e memorial, e, de certa maneira, uma homenagem à professora na residência dos ex-alunos.

Entretanto, nem todos os objetos que eram de Lyuba estão expostos ao olhar do público, alguns são mais íntimos, pois apenas as pessoas selecionadas podem vêlos. Eles possuem um lugar especial dentro da casa, e são guardados com maior segurança, como pequenos tesouros. São carregados de questões simbólicas e imateriais. Muitas vezes estes lugares são gavetas, caixas, álbuns que guardam objetos, fotografias, documentos e tantos outros suportes que funcionam como evocadores memoriais e identitários,

[...] o armário e suas prateleiras, a escrivaninha e suas gavetas, o cofre e seu fundo falso são verdadeiros órgãos da vida psicológica secreta. Sem esses "objetos" e alguns outros igualmente valorizados, nossa vida íntima não teria um modelo de intimidade. São objetos mistos, objetos-sujeitos. Têm, como nós, por nós e para nós, uma intimidade (BACHELARD, 1993, p. 91).

O casal Flavio e Nubia Hanciau hoje salvaguardam outros objetos de Lyuba Duprat que, diferente dos analisados até agora, não estão expostos ao olhar dos visitantes e não são utilizados na rotina da casa. Em primeiro lugar analisaremos uma "caixa de memória", pois dentro dela está guardada uma diversidade de vestígios que pertenceram à Lyuba Duprat. São vistos pela senhora Nubia como valiosos, não pelo valor financeiro, mas pela importância que tinham na vida de Lyuba e para quem os guarda atualmente.

O cargo de guardião desses objetos está diretamente ligado às responsabilidades de preservar os suportes materiais e, consequentemente, as memórias e histórias ali presentes. Por isso há a preocupação em preservar a integridade material, pois eles são testemunhos, são documentos e pontes físicas da 
memória da professora Lyuba. Os "guardiões da memória" seriam, segundo Jean Kellerhals, aqueles que se encarregam da "preservação dos traços - escritos, orais, materiais - do passado familiar" (KELLERHALS, 2002, p. 553). Eles são essenciais para uma transmissão memorial que, no caso dos autores, é baseada principalmente na transmissão familiar e geracional. Mesmo não sendo o caso específico trazido aqui, com relação à Nubia, Flavio, Ricardo e os objetos de Lyuba, por não serem familiares da professora, tratam-se de pessoas que, de certa maneira, assumiram o papel de guardião da memória e dos materiais de Lyuba Duprat e por terem sido muito próximos à ela, gerando um sentimento familiar por eles mesmo narrado.

Nesse sentido, os objetos encontrados na caixa preservam e contam através da narrativa de Nubia Hanciau algumas características da professora. Talvez estes objetos estejam guardados fora do olhar do público para respeitar e preservar sua intimidade natural deles, pois são anotações que podemos categorizar como íntimas da professora Duprat. Reflexões, pensamentos, ideias que ela anotava, endereços de amigos e familiares e datas de aniversário. Estes manuscritos guardam em suas linhas e entrelinhas uma intimidade muito maior do que aqueles objetos que estão expostos ao olhar na sala de estar, e também não ficavam expostos na sala de Lyuba.

Nubia e Flavio tiveram o cuidado de guardar esses objetos em um lugar com a mesma intimidade, acobertados por uma caixa onde juntos criam um contexto: a caixa com as coisas da Lyuba. Um conjunto de figuras e folhetos sobre história da moda, teatro e comportamento que pertenciam à professora, são testemunhos dos materiais recolhidos e utilizados por Lyuba durante os mais de 70 anos de docência.

Um documento em especial, que faz parte desta caixa, também possui o caráter de relíquia: trata-se do documento original expedido em 1992 pela Câmara Municipal de Vereadores, convidando a professora Lyuba Duprat para uma cerimônia que foi realizada para homenageá-la e parabenizá-la pelos 75 anos de atuação no magistério. Dessa forma, lembro da reflexão de Marcus Dohmannn, o qual aborda que mesmo que os objetos não sejam mais utilizados pela sua função prática, eles continuam veiculando e transmitindo informações sobre os sujeitos e estamos sempre atribuindo valores simbólicos a eles (DOHMANN, 2013).

Além do documento ainda existem outros que são objetos e manuscritos guardados e agrupados dentro da caixa. Ela é guardada e referida com afeição pelos seus proprietários, eé mais um local que faz parte da trajetória dos objetos e da biografia cultural dos pertences de Lyuba Duprat. Dessa forma, alguns objetos podem 
ser utilizados como pontos de partida para narrar algo, tanto sobre a vida do narrador, quanto de outras pessoas. Essa capacidade é explorada por Janet Hoskins (1998), a autora demonstra como um grupo de indivíduos utiliza seus objetos mais próximos, aqueles mais afetivos, para contar suas trajetórias de vida - são os objetos autobiográficos.

Baseada no conceito de "objetos biográficos" de Violette Morin, Hoskins percebeu que aqueles mais íntimos eram vistos quase como pessoas, com características "próprias" de seus donos. Os objetos biográficos envelhecem com o seu dono, servem como representação da passagem do tempo e, principalmente, da sua identidade. Eles são reconhecidos com mais facilidade pelas pessoas próximas de seus proprietários, mostram-se mais representativos para sua família e amigos (HOSKINS, 1998). Dessa forma, muitos dos objetos de Lyuba Duprat estudados aqui podem ser entendidos como biográficos, representativos de sua proprietária e fortes indicadores de sua história de vida e memória. Quando repassados por ela, ainda em vida, para seus amigos, continuaram sendo sua representação, recebendo novos contextos e funções.

Esses objetos mencionados continuam sendo biográficos, mesmo que fora do seu contexto de "origem", pois são âncoras narrativas e biográficas, e, por isso, não se desvinculam totalmente da imagem de Lyuba Duprat. Auxiliares narrativos, os objetos tornaram-se veiculadores de histórias de vida (a de Lyuba e de seus novos guardiões) que passam a estar interligadas não só na memória, mas na materialidade dos objetos que foram herdados. A posição desses objetos nos seus novos lares é, como mostrado anteriormente, também uma posição estratégica: alguns estão perto do olhar, da rotina e do dia-a-dia das famílias dos entrevistados. Nubia Hanciau, em seu depoimento escrito para esta pesquisa, corrobora as reflexões trazidas acima:

[...] vemos Lyuba pelos cantos da nossa casa, se restabelece um diálogo restaurador - mesmo que duas décadas de sua morte tenham transcorrido ano passado -, através dos objetos legados, esparsos estrategicamente aqui e ali... Como se cada um se decompusesse em vários, um quebra-cabeça, cada peça repleta de detalhes e de possibilidades narrativas. Eles são pretextos para um retorno, um olhar para trás, uma volta em flashes capazes de refazer parte importante da vida, de provocar analogias que acontecem naturalmente e não podem ser evitadas ${ }^{4}$.

\footnotetext{
${ }^{4} \mathrm{HANCIAU}$, Nubia. Breve depoimento escrito para Olivia Nery, janeiro de 2015.
} 
Os objetos herdados são vistos também como uma representação da professora em sua residência. A maioria destes objetos não é mais utilizada somente de acordo com suas funções originais e estão envolvidos com as histórias e memórias dos sujeitos - desde o casal Flavio e Nubia Hanciau e Ricardo Soler, como seus familiares e amigos e, claro, Lyuba Duprat. Eles adquiriram novas funções e "[...] no rastro das mudanças de sentido dos objetos, encontramos as ações dos sujeitos sociais, ativos construtores de memória" (GOMES e OLIVEIRA, 2010, p. 44). Assim, os novos proprietários dos pertences de Lyuba Duprat, constroem e fortalecem a cada narrativa a memória da professora, principalmente a partir da perspectiva de Pomian, quando afirma que "a linguagem permite falar dos mortos como se estivessem vivos, dos acontecimentos passados como se fossem presentes, do longínquo como se fosse próximo e do escondido como se fosse manifesto" (POMIAN, 1984, p. 68).

Os objetos são também testemunhos, representativos de algo ausente. No caso dos objetos estudados aqui, são marcadores da passagem de Lyuba na vida do casal Hanciau e de Ricardo Soler, e, de certa forma, ela permanece ali, sua memória é representada pelos seus objetos encontrados na casa.

\section{Objetos e emoção por todos os lados, aspectos conclusivos.}

Ao acompanharmos a trajetória desses objetos até a casa dos entrevistados, percebemos que, mesmo não estando em espaços abertos ao público, como museus, eles funcionam como fortalecedores, compartilhadores de memória, história e esquecimento. Acabaram tornando-se a materialização do afeto que sentem pela professora Lyuba Duprat. Chegamos a essa conclusão não só na visita realizada durante a entrevista nas duas residências, mas pensando em todos os outros diálogos que provavelmente aconteceram sobre estes objetos, com outras pessoas, familiares e amigos, que frequentaram a casa dos entrevistados. Assim, os objetos de Lyuba Duprat continuam com sua vida e trajetória, seus ciclos, não restritos somente à sua função utilitária, mas auxiliando na manutenção da memória e da personalidade da professora.

Para concluir esse ensaio e a reflexão aqui proposta, peço licença para falar em primeira pessoa com o leitor sobre a carga memorial e afetiva dos objetos salvaguardados pelos guardiões apresentados aqui. Durante a entrevista na casa do casal Hanciau, sabendo da importância daqueles objetos e de seus significados tanto 
para eles, quanto para mim enquanto pesquisadora e observadora dos fenômenos da memória, Nubia, gentilmente, ofereceu-me um suco em uma das taças de Lyuba.

Figura 4

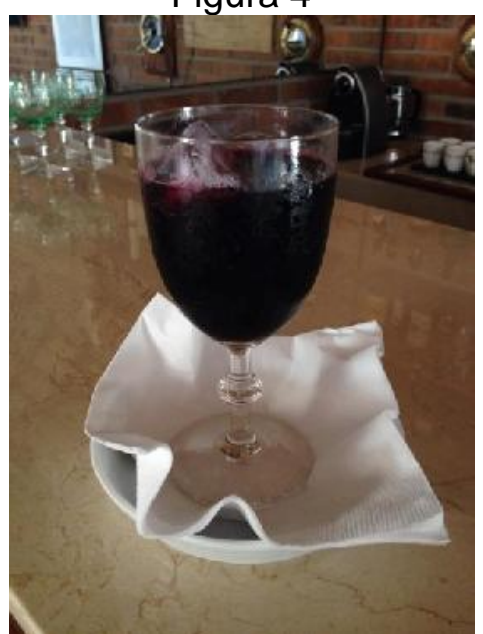

Taça de Lyuba Duprat em uso, 2014. Fonte: Foto da Autora, 2014. Objeto pertencente ao Sr. Flavio e Sra. Nubia Hanciau

Tratava-se de um momento único, singular e extremamente simbólico. Naquele momento, eu, como pesquisadora atenta à relação do casal às coisas que pertenciam a professora, me vi no outro lado do "palco". Aquele momento de conexão física entre mim, a taça, e Lyuba Duprat, me afetou. Talvez, por ter fortalecido o meu vínculo com o objeto de pesquisa, mas creio que, principalmente, pude entender com mais profundidade o que os objetos podem representar na nossa vida e o poder que eles têm sobre nós. Reforço tal sentimento com mais um trecho de Clarice Lispector: "[...] comprei uma coisa pela qual perdidamente me apaixonei: o preço não importa, esse objeto vale o ar" (LISPECTOR, 1999, p. 113). Concordando, concluo: alguns objetos, independentemente de sua forma, valor monetário, valem a nossa vida, nosso ar.

\section{Referências}


BACHELARD, Gaston. A poética do espaço. São Paulo: Martins Fontes, 1993.

BONNOT, Thierry. L’attachement aux chose. Paris: CNRS Éditions, 2014. pp. 7-16.

BOSI, Ecléa. Memória e sociedade: lembranças dos velhos. São Paulo: Companhia das Letras, 1994.

DASSIÉ, Véronique. Objects d'affection: une ethnologie de l'intime. Paris: Éditions du Comité des travaux historiques et scientifiques, 2010.

DOHMANN, Marcus. A experiência material: a cultura do objeto. Rio de Janeiro: Rio Books, 2013.

FERREIRA, Maria Letícia. M. "Objetos, lugares de memória”. In: MICHELON, F. F., et. al. Fotografia e memória: ensaios. Pelotas: Ed. da UFPel, 2008.

Flavio Hanciau. Rio Grande/RS. 18 de janeiro de 2015. Entrevista concedida à Olivia Silva Nery.

GOMES, Alexandre. O.; OLIVEIRA, Ana Amélia R.. A construção social da memória e o processo de ressignificação dos objetos no espaço museal. In: Revista Eletrônica do Programa de Pós-Graduação em Museologia e Patrimônio, v. 3, n. 2, jul/dez 2010.

GONÇALVES, José Reginaldo Santos; BITAR, Nina Pinheiro e GUIMARÃES, Roberta Sampaio [orgs.]. A alma das coisas: patrimônio, materialidade e ressonância. Rio de Janeiro: Mauad X: Faperj, 2013.

GONÇALVES, José. Reginaldo. "Ressonância, materialidade e subjetividade: as culturas como patrimônios". In: Horizontes Antropológicos, Porto Alegre, ano 11, n. 23, p. 15-36, jan/jun 2005.

HANCIAU, Nubia. Breve depoimento escrito para Olivia Nery, janeiro de 2015.

HOSKINS, Janet. Biographical objects: how things tell stories of peoples' lives. London: Routledge, 1998.

IGLESIA, Rafael E. La vida domestica y los objetos. Seminário de Crítica. Instituto de Arte Americano e Investigações Estéticas. oㅜ 165, 2011.

KELLERHALS, Jean, FERREIRA, Cristina, PERRENOUD, David. Linguagens do parentesco: lógicas da construção identitária.In: Análise social, vol XXXVII, 2002, pp. $-545-567$.

KOPYTOFF, Igor. "A biografia cultural das coisas: a mercantilização como processo". In: APPADURAI, Arjun. 2008. A vida social das coisas: as mercadorias sob uma perspectiva cultural. Niterói: EdUFF, 2008.

LISPECTOR, Clarice. Um sopro de vida. Rio de Janeiro: Rocco, 1999. 
MAUSS, Marcel. Ensaio sobre a dádiva. In: Sociologia e antropologia. São Paulo: Cosac Naify, 2003.

MENESES, Ulpiano. T. B. "Memória e cultura material: documentos pessoais no espaço público". In: Revista Estudos Históricos, Rio de Janeiro: Fundação Getúlio Vargas, v.11, n. 21, 1998.

POMIAN, Krzystof. "Coleção". In: ENCICLOPÉDIA EINAUDI, v. 1: Memória - História. Imprensa Nacional: Casa da Moeda, 1984.

Ricardo Antônio Soler. Rio Grande/RS. 07 de março de 2013. Entrevista concedida à Olivia Silva Nery.

SILVEIRA, Flavio Leonel A. e LIMA FILHO, Manuel Ferreira. Por uma antropologia do objeto documental: entre a "alma das coisas" e a coisificação do objeto. In: Horizontes Antropológicos, Porto Alegre, ano 11, n. 23, p. 37-50, jan/jun 2005. 